\title{
Detection of oncogenic mutations in cervical carcinoma using method High Resolution Melting (HRM)
}

\author{
M. WAYHELOVA ${ }^{1,3}$, A. MIKULASOVA ${ }^{1,3}$, J. SMETANA ${ }^{1,3}$, V. VALLOVA ${ }^{1,3}$, D. BLAZKOVA ${ }^{3}$, H. FILKOVA ${ }^{3}$, L. MOUKOVA ${ }^{2}$, P. KUGLIK KI, $^{1, *}$ \\ ${ }^{1}$ Institute of Experimental Biology, Faculty of Science, Masaryk University, Brno, Czech Republic; ${ }^{2}$ Department of Gynecologic Oncology, Masaryk \\ Memorial Cancer Institute, Brno, Czech Republic; ${ }^{3}$ Department of Medical Genetics, University Hospital, Brno, Czech Republic
}

*Corresponding author: kugl@sci.muni.cz

Received November 23, 2015 / Accepted May 9, 2016

\begin{abstract}
Oncogenic mutations in proto-oncogenes and tumor suppressor genes represent one of key events in cancerogenesis. In this study, we analysed mutation status in PIK3CA, KRAS and EGFR proto-oncogenes and TP53 tumor suppressor gene in a cohort of twenty-four patients diagnosed with squamous cell carcinoma or adenocarcinoma using the screening method "High Resolution Melting" (HRM). Positive findings were confirmed and identified by Sanger sequencing. Totally, we detected DNA sequence changes in targeted regions in seven patients $(7 / 24,29.2 \%)$. In PIK3CA gene, we found six sequence changes in four patients $(4 / 24,16.7 \%)$ and four of them were confirmed as oncogenic mutations. In KRAS gene, we detected sequence changes in four patients $(4 / 24,16.7 \%)$. Conversely, we identified pathogenic or potentially pathogenic sequence changes neither in EGFR nor TP53 genes. Our results suggest that sequence changes are specific neither for a certain histological subtype, clinical stage nor lymph node involvement and they appear independently on the presence of HPV (human papillomavirus) infection since early clinical stages. We observed the correlation between the presence of DNA sequence changes and $h T E R C$ gene amplification, but we did not find a significant relationship between the identified DNA sequence changes and detected copy-number alterations using the technique of array-CGH (array-based comparative genomic hybridization).

Regardless our results confirmed an important role of oncogenic mutations in PIK3CA and KRAS genes in the neoplastic transformation process in the cervical carcinoma pathogenesis. Their identification in the early clinical stages should encourage further studies to better understand these mutations and exploit them for more detailed diagnostics.
\end{abstract}

Key words: cervical carcinoma, mutation, high resolution melting, Sanger sequencing

Cervical carcinoma represents one of the most frequent causes of death due to malignancy in women. The overall incidence rate is around 10.6/100 000, its mortality reaches 7/100 000 women in Europe, however, these numbers differ in various regions [1]. Thanks to the general preventive screening programme and early detection of this disease, especially in its precancerous condition, we can observe a slight decrease of the mortality rate [2]. The early detection of a malignant disease especially in its precancerous condition enables to apply an effective therapeutic strategy with a minimum of side effects and to prevent the tumor development to its metastatic phase.

In 70's, the causality between the human papillomavirus infection (HPV) and neoplastic transformation of human cervical epithelial cells was described. More than 100 subtypes of HPV were described and based on their association with the disease development, they can be divided into high-risk and low-risk subtypes. The presence of high-risk subtypes HPV 16 and 18 is detected in about $70 \%$ of patients with cervical carcinoma [3]. Viral proteins deregulate the cell cycle through their binds to proteins which act as tumor suppressors, cyclins and cyclin-dependent kinases [4]. After the elimination of these regulation proteins, damaged and genetically instable cells can survive and this leads to the higher risk for their malignant transformation and progression to more aggressive disease phases.

The process of the malignant transformation affects the cells of the squamous epithelium (squamous cell carcinomas) and adenomatous epithelium (adenocarcinomas) in the uterine cervix. Both the groups differ in their genetic and molecular profiles which results in different clinical characteristics [5]. Adenocarcinomas appear to be related to adverse prognosis with a larger number of distant metastases [6]. 
Cancer cells in both types of cervical carcinoma are characterized by a wide spectrum of genetic abnormalities, from chromosomal copy-number changes to changes in DNA sequence in single genes $[7,8]$. The simultaneous presence of $h T E R C$ gene amplification (3q26) and MYC gene amplification (8q24) was detected recurrently in multiple samples. In previous studies, the significance of mutations in proto-oncogenes and tumor suppressor genes in the initiation and progression of cervical carcinoma was proved, whereas recurrent mutations were identified in mutation "hotspots" in PIK3CA (p.R88Q in exon 1, p.E542K, p.542K, p.Q546E, p.Q546H in exon 9, p.M1043I and p.H1047R in exon 20) $[9,10]$, KRAS (p.G12A, p.G12D, p.G12V, p.G13D in exon 1) [10], EGFR proto-oncogenes (exons 18-21) [11] and in TP53 tumor suppressor gene (codons 173-181, 245249, 273-282) $[12,13]$.

Mutations in PIK3CA gene have an activating oncogenic character with the frequency between $8-31 \%$ in invasive cervical carcinomas $[10,14,15]$. They are typically detected in older patients and therefore they represent a risk factor for the malignant transformed and HPV-infected cell survival. They have not been detected in precancerous cervical cells so far, which may indicate their possible role in progression in the course of early and late disease stages [16]. Moreover, the correlation between the HPV presence and mutation in PIK3CA gene and between the mutation presence and histological subtype of the tumor has not been proved so far $[9,10]$.

Mutations in EGFR gene lead to the signalling pathways activation [17] but they rather represent a rare genetic hit in the cervical carcinoma pathogenesis. They have been identified exclusively in squamous cell carcinomas so far, which may indicate the existence of various molecular mechanisms of the cancerogenesis in certain histological subtypes. The important role of the increased activation of EGFR gene was described in multiple studies but predominantly as a result of gene amplification [18].

The importance of KRAS gene and its activating mutations have been described in multiple tumor pathogeneses including cervical carcinoma. Based on the results of multiple studies, its mutation frequency in cervical carcinoma ranges between $8-18 \%$ whereas considering the histological subtype mutations in KRAS gene have been identified predominantly in adenocarcinomas $[10,19,20]$. In squamous cell carcinomas KRAS gene mutations have been detected rarely. Due to their rare detection the correlation between mutations in KRAS gene and the adverse survival has not been unfailingly observed so far [10].

Somatic mutations in TP53 gene have been identified in a majority of human cancer types with variable frequency. More than $80 \%$ of all mutations occur in exons forming DNA-binding domain. In contrast to ovarian, colorectal or oesophageal cancer with TP53 mutation frequency about $50 \%$, they represent a rather rare genetic event in cervical carcinoma [21]. Due to generally low mutation frequency, its inactivation is mediated by more mechanisms, e.g. the interac- tion between protein p53 and HPV protein E6 and after that p53 is degraded. Acquired mutations in TP53 gene are related to the gain of the aggressive tumor cell phenotype $[22,23]$. Considering the histological subtype of the tumor, a higher mutation frequency of TP53 gene in adenocarcinomas (about $13 \%$ ) in comparison to squamous cell carcinomas (about 6\%) have been proved.

Activating mutations in PIK3CA, KRAS proto-oncogenes, an increased expression of EGFR proto-oncogene and inactivating mutations in TP53 gene are related to the adverse prognosis of the disease $[15,16,24]$. Their identification means potential targets in the research, development and improvement of targeted and personalized therapy.

The aim of this pilot study was to analyse mutation status in PIK3CA, KRAS, EGFR proto-oncogenes and TP53 tumor suppressor gene using a screening method "High Resolution Melting" (HRM). Consequently we evaluated the results of mutation analysis in the relationship to clinical characteristics of the disease. Simultaneously, we studied possible correlations between the gene mutations or DNA sequence changes and the presence of chromosomal abnormalities which were detected by methods of HPV-FISH (fluorescence in situ hybridization for the detection of human papillomavirus in cells) and array-CGH (array-based comparative genomic hybridization) realized in the scope of our previous studies $[7,25]$.

\section{Materials and methods}

In our study, we analysed cervical carcinoma samples from twenty-four patients diagnosed at the Department of Gynecologic Oncology in the Masaryk Memorial Cancer Institute (median age 42 years, range 38-63 years) which were obtained since 2009 to 2013.

All samples were obtained only after the patients signed the informed consent approved by the Ethical committee of the MMCI and were immediately frozen in liquid nitrogen. Patients after surgical procedures and any adjuvant treatment were monitored in regular intervals according to onco-gynecological guidelines [26]. The basic clinical characteristics of the analysed cohort of patients are summarized in Table 1.

Genomic DNA samples for the molecular cytogenetic and molecular genetic purposes were isolated using standard phenol extraction and consequently, we evaluated their quality and quantity by DNA agarose electrophoresis with TrackIt $1 \mathrm{~Kb}$ Plus DNA Ladder (Thermo Fisher Scientific) (Figure 1) and NanoDrop ${ }^{\circ}$ ND-1000 (Thermo Fisher Scientific) and Qubit ${ }^{\circ}$ 1.0 (Thermo Fisher Scientific).

Molecular cytogenetic analysis by FISH technique was accomplished using the commercial kit Vysis Cervical FISH Probe (Abbott Molecular, Illinois, USA). The kit enables the simultaneous detection of HPV-infected cells and the amplification of chromosomal regions 3q26 ( $h T E R C$ gene) and 8q24 (MYC gene) as described previously [7, 25]. For the whole-genome screening of chromosomal abnormalities by array-CGH, we used a platform of oligonucleotide-based 
DNA microarrays SurePrint G3 CGH+SNP Array 180K (Agilent Technologies, Santa Clara, CA, USA). The methodology and complete results are described in details in Kuglik et al (2014) [7].

Mutation status of given genes was analysed using the screening method "High Resolution Melting" (HRM) followed by Sanger sequencing as a routinely used method for the confirmation and exact identification of DNA sequence changes. For our purpose, we used the commercially available reaction kit MeltDoctor ${ }^{\mathrm{TM}}$ HRM Master Mix (Thermo Fisher Scientific, Waltham, MA, USA) and termocycler StepOne ${ }^{\mathrm{TM}}$ Real-time PCR System (Thermo Fisher Scientific, Waltham, MA, USA). For the primer design for real-time PCR with HRM analysis and their verification, we used bioinformatic databases NCBI and UCSC Genome Browser and online tools Primer3, UCSC In-Silico PCR, PrimerBlast and $\mathrm{uMelt}^{\mathrm{SM}}$ - DNA Melting Curve Prediction. Using these databases and online tools, we designed twelve primer pairs (three pairs for mutation "hotspots" in PIK3CA gene, one pair for mutation "hotspot" in exon 1 in KRAS gene, five

Table 1. The clinical and molecular cytogenetic characteristics of the cohort of 24 patients with cervical carcinoma.

\begin{tabular}{|c|c|c|}
\hline Feature & Parameter & Incidence \\
\hline \multirow{2}{*}{ histological subtype } & adenocarcinoma & $6(25 \%)$ \\
\hline & squamous cell carcinoma & $18(75 \%)$ \\
\hline \multirow{2}{*}{ HPV status } & \multirow{2}{*}{$\begin{array}{l}\text { positive } \\
\text { negative }\end{array}$} & $20(83.3 \%)$ \\
\hline & & $4(16.7 \%)$ \\
\hline \multirow{7}{*}{ clinical stage (FIGO) } & \multirow{4}{*}{$\begin{array}{l}\text { IA1 } \\
\text { IA2 } \\
\text { IB1 } \\
\text { IB2 }\end{array}$} & $1(4.2 \%)$ \\
\hline & & $2(8.3 \%)$ \\
\hline & & $11(45.8 \%)$ \\
\hline & & $2(8.3 \%)$ \\
\hline & II & $0(0 \%)$ \\
\hline & IIIB & $7(29.2 \%)$ \\
\hline & IVA & $1(4.2 \%)$ \\
\hline \multirow{8}{*}{$\begin{array}{l}\text { lymph node with } \\
\text { metastases }\end{array}$} & 0 & $14(58.3 \%)$ \\
\hline & 1 & $2(8.3 \%)$ \\
\hline & 2 & $1(4.2 \%)$ \\
\hline & 3 & $1(4.2 \%)$ \\
\hline & 4 & $1(4.2 \%)$ \\
\hline & 7 & $1(4.2 \%)$ \\
\hline & 13 & $1(4.2 \%)$ \\
\hline & not investigated & $3(12.5 \%)$ \\
\hline \multirow{3}{*}{$\begin{array}{l}\text { MYC gene amplification } \\
\text { (FISH) }\end{array}$} & amplification & $15(62.5 \%)$ \\
\hline & no amplification & $8(33.3 \%)$ \\
\hline & not investigated & $1(4.2 \%)$ \\
\hline \multirow{3}{*}{$\begin{array}{l}\text { hTERC gene amplification } \\
\text { (FISH) }\end{array}$} & amplification & $20(83.3 \%)$ \\
\hline & no amplification & $3(12.5 \%)$ \\
\hline & not investigated & $1(4.2 \%)$ \\
\hline \multirow{4}{*}{$\begin{array}{l}\text { copy-number alterations } \\
\text { (CNAs) } \\
\text { (array-CGH) }\end{array}$} & $0-5$ & $14(58.3 \%)$ \\
\hline & $6-10$ & $6(25 \%)$ \\
\hline & $11-15$ & $1(4.2 \%)$ \\
\hline & more than 15 & $3(12.5 \%)$ \\
\hline
\end{tabular}

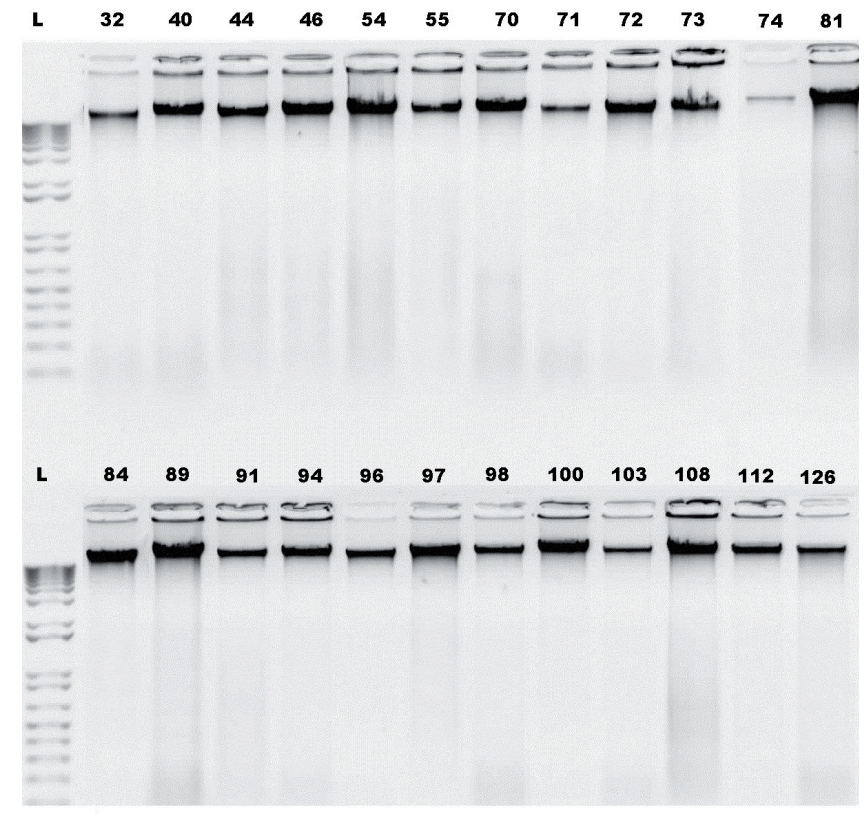

Figure 1. DNA agarose electrophoresis with genomic DNA samples. The DNA samples integrity was estimated to be sufficient for HRM and PCRbased analyses. Glossary: L - TrackIt ${ }^{\mathrm{mit}} 1$ kb Plus DNA Ladder, 32-126 - DNA samples.

pairs for exons 18-21 in EGFR gene and three pairs for mutation "hotspots" in TP53 gene). Primers were synthetized by Sigma Aldrich (St. Louis, MO, USA). Consequently, we confirmed their specificity by DNA agarose electrophoresis $(1,2 \%$ gel, $100 \mathrm{~V} / 60 \mathrm{~min})$. Their overview is presented in Supplementary Table 1.

The primer design, sample preparation and experimental conditions were set according to the manufactory recommendation (Thermo Fisher Scientific, Waltham, MA, USA). Data were processed using the StepOneTM Software v2.3 and High Resolution Melt Software v3.0.1 (Thermo Fisher Scientific, Waltham, MA, USA). DNA samples tested positively via mutation screening by HRM were consequently processed for Sanger sequencing. First, we prepared long DNA amplicons using the second primer set which were designed for the purposes of standard PCR (Promega, Madison, WI, USA) and Sanger sequencing. PCR products were purified using Exonuclease I and FastAP Thermosensitive Alkaline Phosphatase following manufactory recommendation (Thermo Fisher Scientific, Waltham, MA, USA). Primers were synthetized by Sigma Aldrich (St. Louis, MO, USA). The overview of primer pairs for standard PCR and Sanger sequencing is presented in Supplementary Table 2.

Consequently, we performed the termination reaction to obtain ssDNA fragment library for Sanger sequencing (BigDye Terminator v3.1 Cycle Sequencing Kit following manufactory recommendation, Thermo Fisher Scientific, Waltham, MA, USA). Sequencing reactions were performed in 

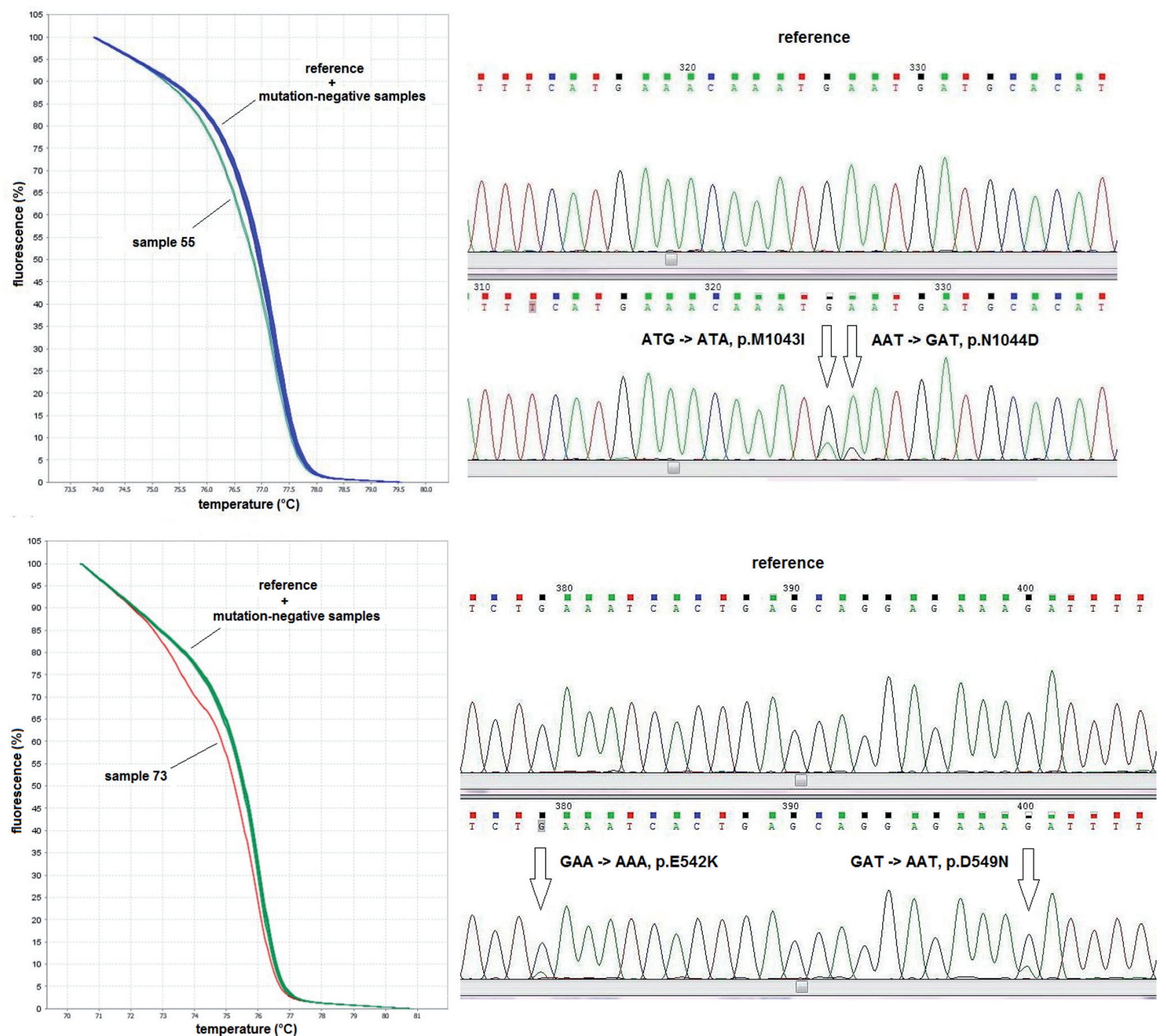

Figure 2. Mutation analyses of "hotspot" regions in PIK3CA gene using methods HRM (left) and Sanger sequencing (right). There is shown a melt curves shift in samples 55 (up) and 73 (down) in comparison with reference DNA sample and patients' samples with no DNA sequence changes. On the right there are shown graphical results from Sanger sequencing.

the capillary electrophoresis DNA sequencer ABI 3130 (Thermo Fisher Scientific, Waltham, MA, USA). Chromatograms were analysed using the software Sequencher 5.1 (Gene Codes Corporation, Ann Arbor, MI, USA) and Chromas Lite v2.1 (Technelysioum Pty Ltd, South Brisbane, Australia). To predict an effect of mutation, we used online tool PROVEAN (http:// provean.jcvi.org/index.php) with threshold -2.5 (a higher value predicts a neutral effect and a lower or threshold value predicts a pathogenic effect, http://provean.jcvi.org/about. php\#about_1b).

\section{Results}

In this pilot study, we analysed DNA sequence changes in mutation "hotspots" in PIK3CA, KRAS, EGFR proto-oncogenes and TP53 tumor suppressor gene in the tumor DNA samples obtained from twenty-four patients with cervical carcinoma.

In the course of mutation "hotspots" analyses in PIK3CA gene, we detected differences in melting curve profiles compared to reference DNA melting curve profile in four patients. 
Consequently, we managed to identify four point heterozygous mutations by Sanger sequencing. In one patient, we detected two DNA sequence changes resulting in the substitution of glutamic acid to lysine in the position 542 on the protein level (p.E542K) and aspartic acid to asparagine in the position 549 on the protein level (p.D549N). In the other patient, again, we detected two DNA sequence changes characterized by the substitution of methionine to isoleucine in the position 1043 on the protein level (p.M1043I) and asparagine to aspartic acid in the position 1044 on the protein level (p.N1044D). Based on the result of Sanger sequencing, it is clear that all the detected point mutations are likely to occur in minor clones of tumor cells (Figure 2).

We also analysed mutation "hotspots" in KRAS and TP53 genes and mutation occurrence in exons 18, 19, 20 and 21 in EGFR gene using HRM method. We detected DNA sequence changes in exon 1 of KRAS gene in four patients' tumor DNA samples $(4 / 24,16.7 \%)$. However, we confirmed none of them by Sanger sequencing. In EGFR and TP53 genes, we detected only common benign SNPs and consequently, all of them were proved by Sanger sequencing.

The positive findings, obtained by the mutation screening by HRM and Sanger sequencing, respectively, were analysed in the context to clinical characteristics and results of molecular cytogenetic investigations. DNA sequence changes in PIK3CA and KRAS proto-oncogenes were detected in five patients with squamous cell carcinoma $(5 / 18,27.8 \%)$ and in two patients with adenocarcinoma $(2 / 6,33.3 \%)$, whereas DNA sequence changes occurring in gene PIK3CA were identified only in patients with squamous cell carcinoma. In contrast to gene PIK3CA gene mutations in mutation "hotspot" in exon 1 of KRAS gene were detected in two patients with squamous cell carcinoma and in two patients with adenocarcinoma as well. Moreover, in these two patients with adenocarcinoma, we did not detect the presence of HPV infection.

The results were consequently evaluated with regard to the clinical stage of the disease according to FIGO classification. Based on the clinical investigation, three patients harbouring either DNA sequence changes or point mutations in PIK3CA gene were grouped to the stage I (IA2, IB1) and one patient was grouped to the stage IIIB. Two patients harbouring DNA sequence changes in mutation "hotspot" in KRAS gene were grouped to stage I (IA2, IB1) and IIIB, respectively. None of the patients with positive HRM screening results were grouped neither to stages II nor IV. Despite a small group of patients, we can observe a tendency to occurrence of pathogenic/potentially pathogenic mutations in genes PIK3CA and KRAS since the early stages of cervical carcinomas.

In both patients in the clinical stage IIIB, we observed metastases in two and three lymph nodes, respectively. In the rest of the patients harbouring mutations or DNA sequence changes in PIK3CA and/or KRAS genes, we did not detect the metastases in any lymph nodes.

Consequently we studied an association between the cytogenetic findings and results obtained by mutation analyses. The hTERC gene amplification was observed in all the seven

Table 2. The summary of mutation analysis results in individual patients and their context to clinical data and to results obtained by molecular cytogenetic analyses.

\begin{tabular}{|c|c|c|c|c|c|c|c|c|c|c|c|c|}
\hline \multirow[b]{2}{*}{ 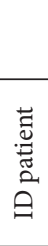 } & \multicolumn{4}{|c|}{ Clinical characteristics } & \multicolumn{5}{|c|}{ Molecular cytogenetic analyses } & \multicolumn{3}{|c|}{$\begin{array}{c}\text { Mutation screening by HRM } \\
\text { and Sanger sequencing }\end{array}$} \\
\hline & 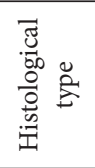 & 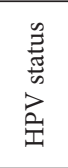 & ○ & 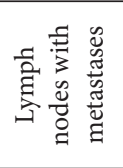 & 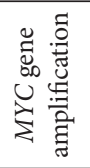 & 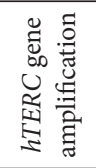 & 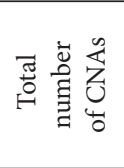 & 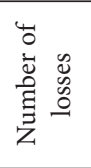 & 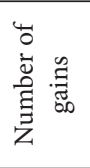 & 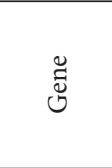 & 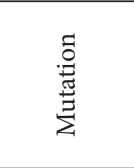 & 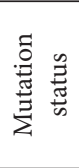 \\
\hline 54 & S & pos & IIIB & 2 & neg & pos & 19 & 10 & 9 & KRAS & nd & - \\
\hline \multirow{2}{*}{55} & \multirow{2}{*}{$S$} & \multirow{2}{*}{ pos } & \multirow{2}{*}{ IB1 } & \multirow{2}{*}{ nd } & \multirow{2}{*}{ pos } & \multirow{2}{*}{ pos } & \multirow{2}{*}{1} & \multirow{2}{*}{0} & \multirow{2}{*}{1} & \multirow{2}{*}{ PIK3CA } & p.M1043I & het \\
\hline & & & & & & & & & & & p.N1044D & het \\
\hline \multirow{2}{*}{73} & \multirow{2}{*}{$S$} & \multirow{2}{*}{ pos } & \multirow{2}{*}{ IB1 } & \multirow{2}{*}{0} & \multirow{2}{*}{ pos } & \multirow{2}{*}{ pos } & \multirow{2}{*}{19} & \multirow{2}{*}{0} & \multirow{2}{*}{19} & \multirow{2}{*}{ PIK3CA } & p.E542K & het \\
\hline & & & & & & & & & & & p.D549N & het \\
\hline 74 & A & neg & IIIB & 3 & pos & pos & 0 & 0 & 0 & KRAS & nd & - \\
\hline \multirow{2}{*}{98} & \multirow{2}{*}{ S } & \multirow{2}{*}{ pos } & \multirow{2}{*}{ IA2 } & \multirow{2}{*}{0} & \multirow{2}{*}{ neg } & \multirow{2}{*}{ pos } & \multirow{2}{*}{0} & \multirow{2}{*}{0} & \multirow{2}{*}{0} & PIK3CA & nd & - \\
\hline & & & & & & & & & & KRAS & nd & - \\
\hline 100 & A & neg & IB1 & 0 & pos & pos & 0 & 0 & 0 & KRAS & nd & - \\
\hline 103 & S & pos & IIIB & 1 & neg & pos & 1 & 0 & 1 & PIK3CA & nd & - \\
\hline
\end{tabular}

Glossary: S - squamous cell carcinoma, A - adenocarcinoma, neg - negative, pos - positive, CNAs - copy-number alterations, nd - not defined, het - heterozygous mutation 
patients with positive results obtained by mutation analyses $(7 / 7,100 \%)$ as $M Y C$ gene amplification was detected in four patients $(4 / 7,57.1 \%)$. The simultaneous amplification of $M Y C$ and $h T E R C$ genes was identified in both the patients with the closely specified PIK3CA gene mutations. In other two patients harbouring DNA sequence changes in PIK3CA gene, we did not detect $M Y C$ gene amplification. Simultaneous $M Y C$ and $h T E R C$ genes amplification was detected in two patients harbouring DNA sequence change in mutation "hotspot" in KRAS gene. The results obtained by mutation analyses in the context to clinical and molecular cytogenetic data are summarized in Table 2.

All the patients underwent whole-genome screening by array-CGH method for detection of unbalanced chromosomal aberrations (CNAs; Copy-Number Alterations), i.e. losses and gains of genetic material. We assessed the whole-genome profile of losses and gains of DNA sequences for every individual patient. These results were evaluated in context to results obtained using mutation analyses.

We did not find a statistical significance between the number of CNAs and DNA sequence changes in PIK3CA and KRAS genes. In three patients with detected DNA sequence changes in the course mutation analyses, no CNAs was found and we detected one CNA (gain $8 \mathrm{q}$ and gain $17 \mathrm{q}$, respectively) in two patients. In other two patients, we found more than fifteen CNAs whereas in one patient harbouring DNA sequence change in KRAS gene, we identified ten losses and nine gains of genetic material in chromosomal regions and in the other patient harbouring point mutations in PIK3CA gene (p.E542K a p.D549N), we detected nineteen gains of genetic material in chromosomal regions. The complete results of genomic profiling of our cohort of patients by array-CGH method was described elsewhere [7]. The summary of results of mutation analyses and their context to clinical data and results obtained by HPV-FISH and whole-genome screening by array-CGH as well is listed in Table 2.

\section{Discussion}

In the course of our previous studies, we proved that specific genomic alterations, especially gains of genetic material in MYC and $h T E R C$ gene loci together with HPV infection play an important role in the neoplastic transformation of epithelial cells of uterine cervix[7]. We steadily continue with this study which is focused on mutation status analyses of PIK3CA, KRAS and EGFR proto-oncogenes and TP53 tumor suppressor gene using HRM screening method. Totally, we found point mutations or potentially pathogenic DNA sequence changes in seven patients. In four patients, we detected DNA sequence changes in two mutation "hotspots" in exons 9 and 20 of PIK3CA gene and in four patients, we identified DNA sequence changes in mutation "hotspot" in exon 1 of KRAS gene.

PIK3CA gene encodes p110 $\alpha$ catalytic subunit $(110 \mathrm{kDa})$ of phosphatidylinositol 3-kinase (PI3K), an essential part of signalling pathway $\mathrm{PI} 3 \mathrm{~K} / \mathrm{AKT} / \mathrm{mTOR}$ which is important for cell cycle progression, cell proliferation and survival, as well. It was proved that dysregulation of this signalling pathway by various genetic mechanisms results in its constitutive activation leading to changes in regulation of essential cell processes. Beside activating point mutations affecting PIK3CA gene, its amplification was observed as an activating mechanism in some types of tumors, as well [27]. In this study, we analysed its three mutation "hotspots" and their adjacent DNA sequences. We detected DNA sequence changes in four patients (16.7\%) and in two of them, we described these DNA sequence changes as four point heterozygous mutations p.E524K, p. D549N, p.M1043I a p.N1044D. Mutation p.E542K has been already proved as pathogenic with constitutively activating effect in PI3K/AKT/mTOR signalling pathway in a large number of tumor diseases [28]. In contrast to this well characterized point mutation, the other mutation p.D549N has been described only in a few cases of colorectal carcinoma, breast or endometrial carcinoma so far [29-31]. Concerning to its low frequency, the information about its effect in the protein function is still absent. Therefore, based on in silico prediction by PROVEAN, we evaluated the mutation effect as neutral on the protein function (PROVEAN score -2,355). Whyte et al. (2006) identified this mutation in tumor cell line HCT-15 derived from large intestine and in the same sample, they detected point mutation p.E545K previously characterized as pathogenic, with constitutively activating effect on kinase AKT [32-34]. In our study, we detected mutation p.D549N in one tumor DNA sample together with oncogenic mutation p.E542K. According to Whyte et al. (2006), this mutation p.D549N may function as a "passenger" in the process of malignant transformation without a direct contribution to the gain of the malignant phenotype of the cell clone [32]. In the other patient, we also detected two point mutations in PIK3CA gene. Mutation p.M1043I was described in previous studies as oncogenic [9]. Mutation p.N1044D has been detected only in a few cases of large intestine carcinoma, endometrial carcinoma and glioblastoma so far [34-36]. Using in silico tool PROVEAN, we evaluated its effect on the protein function as neutral (PROVEAN score -0.458).

In the context to the histological subtype, we identified point mutations and potentially pathogenic DNA sequence changes, respectively, in PIK3CA gene in four patients with squamous cell carcinoma but not in patients with adenocarcinoma. The study by Miyake et al. (2008) did not prove the occurrence of PIK3CA gene mutation exclusively in a particular histological subtype, as well [34]. Simultaneously, our results agree with the results obtained in study by Cui et al. (2009) and indicate that PIK3CA gene mutations are specific neither for HPV-positive nor HPV-negative cervical carcinoma samples [9]. We observed the correlation between the presence of PIK3CA gene mutations and hTERC (3q26) gene amplification. This fact indicates that gene mutations contribute to the development of malignant phenotype. Conversely, we cannot prove a significant context between 
PIK3CA gene mutation presence, the number of CNAs or $M Y C$ (8q24) gene amplification. No study has analysed the relationship between PIK3CA gene mutations and numeric changes in chromosomal region $3 \mathrm{q}$ harbouring PIK3CA gene (3q26.3) so far.

Based on the data in the study by Cui et al. (2009) mentioned above, the presence of PIK3CA gene mutation may represent a risk factor in combination with an invasive type of carcinoma for older patients (above 60 years). In younger patients, cervical carcinomas are more frequently related to HPV infection. This fact indicates a possible evidence for more mechanisms of cancerogenesis and risk factors in cervical carcinoma. In our patients' group, this hypothesis is declared by a presence of two PIK3CA gene mutations (p.M1043I a p.N1044D) in one older patient (68 years) but without an invasive type of cervical carcinoma and with HPV infection positivity. Point mutations and potentially pathogenic DNA sequence changes in PIK3CA gene were detected in three patients in clinical stage I (IA2, IB1) and in one patient in clinical stage IIIB. The study by Tornesello et al. (2014) showed impaired effect of PIK3CA gene mutations in the context to shorter survival in patients in clinical stage IB/II who had undergone radical chemotherapy [16]. This effect was not observed in patients in clinical stage III/ IV probably due to generally impaired survival in patients in advanced clinical stages.

PIK3CA gene mutations or potentially pathogenic DNA sequence changes in this gene were analysed in the context to the presence of lymph nodes affected by metastases and their number. We did not observe any metastatically affected lymph nodes in these patients but the results of a recent study by Hou et al. (2014) confirm the outcomes from the previous studies indicating the correlation between the higher frequency of PIK3CA gene mutations and metastases presence [37]. High mutation prevalence in PIK3CA gene enables to use this gene as a potential molecular target for targeted therapy with PI3K/ AKT/mTOR inhibitors, leading to a higher therapeutic response $[10,38]$. Our analytical approach and results could help to define a group of patients with a higher risk of metastatic disease. These patients require an individual attention in clinical monitoring of the disease progression and may compose a target group for targeted therapy application.

KRAS gene encodes a small GTPase protein which creates an essential part of RAS/MAPK signalling pathway. Similarly to $\mathrm{PI} 3 \mathrm{~K} / \mathrm{AKT} / \mathrm{mTOR}$, it represents one of the key signalling pathways which plays an important role in cell proliferation, cell cycle progression and cell survival. The dysregulation of these cell signalizations has been shown to be one of the significant molecular causes in cancerogenesis in a large number of tumor diseases. KRAS gene mutations had been proved in less than $10 \%$ cases of cervical carcinoma and associated with adverse prognosis, especially in patients with squamous cell carcinoma [39]. In the context to the histological subtype, we identified potentially pathogenic DNA sequence changes in KRAS gene in two patients with adenocarcinoma and in two patients with squamous cell carcinoma, as well. Based on the results obtained by several extensive studies, it is not possible to determine the specificity of KRAS gene mutations for a particular histological subtype. Nevertheless, there is a tendency to occur in adenocarcinoma more frequently than in squamous cell carcinoma [10, 40]. Moreover, our data confirm that KRAS gene mutation does not correlate with a particular clinical stage or the presence of HPV infection. In two cases, KRAS mutation was detected in HPV-negative cervical carcinoma samples. This may indicate that the presence of KRAS mutations and $\mathrm{HPV}$ infection presumably represent two independent events in cancerogenesis as suggested in the study of Buyru et al. (2006) [41]. Further studies with large cohorts of patients to clarify this statement are necessary. As well as in the course of PIK3CA gene mutation analysis, we found the correlation between the presence of potentially pathogenic DNA sequence changes in KRAS gene and $h T E R C$ (3q26) gene amplification. Simultaneously, we did not observe a significant correlation between the presence of potentially pathogenic DNA sequence changes in KRAS, the number of CNAs or MYC (8q24) gene amplification.

Janku et al. (2012) proved an increased coincidence of KRAS and PIK3CA genes mutations in cervical carcinoma samples and determined its adverse outcome in therapeutic response, resulting in the resistance to $\mathrm{PI} 3 \mathrm{~K} / \mathrm{AKT} / \mathrm{mTOR}$ pathway inhibitors [38]. In our group of patient we detected a coincidence of potentially pathogenic DNA sequence changes in KRAS and PIK3CA genes in one patient with squamous cell carcinoma. DNA sequence changes in mutation "hotspot" in KRAS gene were found in two patients in clinical stage I (IA2, IB1) and in two patients in stage IIIB. Similarly to mutations in PIK3CA gene, we can observe DNA sequence changes in KRAS gene since the early stages of disease. Based on previous studies on cervical carcinoma and other types of solid tumors, it is clear that oncogenic mutations may contribute to the metastatic potential of cancer cells. This finding may serve for more specific stratification of patients based on the risk of metastatic progression of the disease, for clinical monitoring of individual defined patients. Moreover it may help to profile a group of patients who could be candidates for the application of the targeted therapy by RAS/MAPK pathway inhibitors.

EGFR gene encodes cell-surface receptor for a family of epidermal growth factors. It is a key member of many signalling pathways which stimulate the cell cycle and pathways which stimulate the cell proliferation and survival. The changes in its structure or in a number of its copies were proved as an important aspect in cancerogenesis in a wide spectrum of tumors. In our group of patients, we did not detect a potentially pathogenic DNA sequence change leading to constitutional EGFR protein activity. We detected only common benign SNPs in studied DNA regions and all of them were confirmed by Sanger sequencing. Our results agree with other studies which indicate a rarity of EGFR gene mutations and EGFR gene amplification as more common mechanism for upregulation of EGFR gene expression in cervical carcinoma [24, 42]. 
TP53 gene mutations were described as a key aspect in neoplastic cell transformation in a majority of human tumors, with varying mutation frequency and tumor stages, as well. In cervical carcinoma, they are detected rather rarely, therefore, there has been clearly described neither their prognostic nor predictive role so far [20]. Unsurprisingly, in our group of patients we did not identify any potentially pathogenic DNA sequence changes using HRM.

Generally, the identification of point mutations in prognostically important proto-oncogenes and tumor suppressor genes represents a key aspect for possible application for the targeted therapeutic approach in a defined group of patients. Activating oncogenic mutations are potential molecular targets for design of a specific signalling pathway inhibitor. The implementation of HRM method with positive reference DNA, i.e. reference DNA sample harbouring a known mutation, could offer a fast screening of specific mutations in genes of interest. This could define a group of patients which may profit from the personalized targeted therapy [43-45]. In our study using HRM method lacking positive control DNA samples, Sanger sequencing showed to be insufficient for the confirmation and identification of DNA sequence changes if they appear in minor tumor cell clones under the detection limit.

\section{Summary}

In the course of this study, we have analysed the mutation status in PIK3CA, KRAS, EGFR proto-oncogenes and TP53 tumor suppressor gene in their mutation "hotspots" using HRM screening method and Sanger sequencing as a confirmatory method. In PIK3CA gene we detected two previously described point mutations and other two point mutations without previous evidence in cervical carcinoma. Moreover, we detected two DNA sequence changes in this gene lacking their exact identification using Sanger sequencing. In KRAS gene we identified four potentially pathogenic DNA sequence changes affecting mutation "hotspot" in exon 1. Although our study is based on a small group of patients, current knowledge resulting from mutation analyses confirm the results of previous extensive studies that squamous cell carcinoma and adenocarcinoma differ in their molecular profiles on the level of gene mutations. These findings are expected to be confirmed and specified in the course of studies encompassing larger groups of patients.

Supplementary information is available in the online version of the paper.

\section{References}

[1] KESIC V, POLJAK M, ROGOVSKAYA S. Cervical cancer burden and prevention activities in Europe. Cancer Epidemiol Biomarkers Prev 2012; 21: 1423-1433. http://dx.doi. org/10.1158/1055-9965.EPI-12-0181
[2] DUSKOVA J, BEKOVA A, DVORAK V, MAJEK O, DUSEK L. [Results of the Czech National Cervical Cancer screening programme]. Klin Onkol 2014; 27 Suppl 2: 79-86. http:// dx.doi.org/10.14735/amko20142S79

[3] NOUR NM. Cervical cancer: a preventable death. Rev Obstet Gynecol 2009; 2: 240-244.

[4] YIM EK, PARK JS. The role of HPV E6 and E7 oncoproteins in $\mathrm{HPV}$-associated cervical carcinogenesis. Cancer Res Treat 2005; 37: 319-324. http://dx.doi.org/10.4143/crt.2005.37.6.319

[5] CHAO A, WANG TH, LEE YS, HSUEH S, CHAO AS et al. Molecular characterization of adenocarcinoma and squamous carcinoma of the uterine cervix using microarray analysis of gene expression. Int J Cancer 2006; 119: 91-98. http://dx.doi. org/10.1002/ijc.21813

[6] GALIC V, HERZOG TJ, LEWIN SN, NEUGUT AI, BURKE WM et al. Prognostic significance of adenocarcinoma histology in women with cervical cancer. Gynecol Oncol 2012; 125: 287-291. http://dx.doi.org/10.1016/j.ygyno.2012.01.012

[7] KUGLIK P, SMETANA J, VALLOVA V, MOUKOVA L, KASIKOVA $\mathrm{K}$ et al. Genome-wide screening of DNA copy number alterations in cervical carcinoma patients with CGH+SNP microarrays and HPV-FISH. Int J Clin Exp Pathol 2014; 7: 5071-5082.

[8] KRKAVCOVA M, JANCARKOVA N, JANASHIA M, KRITKOVA A, PEXIDROVA M. Detection and occurence of the chromosomal aberrations in malignant tumors of cervix and ovary. Klin onkol 2006; 19: 124-129.

[9] CUI B, ZHENG B, ZHANG X, STENDAHL U, ANDRESSON S ET AL. Mutation of PIK3CA: Possible risk factor for cervical carcinogenesis in older women. Int J Clin Oncol 2009; 34: 409-416.

[10] WRIGHT AA, HOWITT BE, MYERS AP, DAHLBERG SE, PALESCANDOLO E et al. Oncogenic Mutations in Cervical Cancer Genomic Differences Between Adenocarcinomas and Squamous Cell Carcinomas of the Cervix. Cancer 2013; 119: 3776-3783. http://dx.doi.org/10.1002/cncr.28288

[11] LONGATTO-FILHO A, PINHEIRO C, MARTINHO O, MOREIRA MA, RIBEIRO LF et al. Molecular characterization of EGFR, PDGFRA and VEGFR2 in cervical adenosquamous carcinoma. BMC Cancer 2009; 9: 212. http://dx.doi. org/10.1186/1471-2407-9-212

[12] NGAN HY, TSAO SW, LIU SS, STANLEY M. Abnormal expression and mutation of p53 in cervical cancer--a study at protein, RNA and DNA levels. Genitourin Med 1997; 73: 54-58. http://dx.doi.org/10.1136/sti.73.1.54

[13] TOMMASINO M, ACCARDI R, CALDEIRA S, DONG W, MALANCHI I et al. The role of TP53 in Cervical carcinogenesis. Hum Mut 2003; 21: 307-312. http://dx.doi.org/10.1002/ humu. 10178

[14] JANKU F, LEE JJ, TSIMBERIDOU AM, HONG DS, NAING A et al. PIK3CA mutations frequently coexist with RAS and BRAF mutations in patients with advanced cancers. PLoS One 2011; 6: e22769. http://dx.doi.org/10.1371/journal. pone.0022769

[15] MCINTYRE JB, WU JS, CRAIGHEAD PS, PHAN T, KOBEL $\mathrm{M}$ et al. PIK3CA mutational status and overall survival in patients with cervical cancer treated with radical chemora- 
diotherapy. Gynecol Oncol 2013; 128: 409-414. http://dx.doi. org/10.1016/j.ygyno.2012.12.019

[16] TORNESElLO M, ANNUNZIATA C, BUONAGURO L, LOSITO S, GREGGI S. TP53 and PIK3CA gene mutations in adenocarcinoma, squamous cell carcinoma and high-grade intraepithelial neoplasia of the cervix. J Transl Med 2014; 12: 255. http://dx.doi.org/10.1186/s12967-014-0255-5

[17] FUCHS I, VORSTEHER N, BUHLER H, EVERS K, SEHOULI J. The prognostic significance of human epidermal growth factor receptor correlations in squamous cell cervical carcinoma. Anticancer Res 2007; 27: 959-963.

[18] LI Q, TANG Y, CHENG X, JI J, ZHANG J et al. EGFR protein expression and gene amplification in squamous intraepithelial lesions and squamous cell carcinomas of the cervix. Int J Clin Pathol 2014; 7: 733-741.

[19] KANG S, KIM HS, SEO SS, PARK SY, SIDRANSKY D, DONG SM: Inverse correlation between RASSF1A hypermethylation, KRAS and BRAF mutations in cervical adenocarcinoma. Gynecol Oncol 2007; 105: 662-666. http:// dx.doi.org/10.1016/j.ygyno.2007.01.045

[20] OJESINA AI, LICHTENSTEIN L, FREEMAN SS, PEDAMALLU CS, IMAZ-ROSSHANDLER I et al. Landscape of genomic alterations in cervical carcinomas. Nature 2014; 506: 371-375. http://dx.doi.org/10.1038/nature12881

[21] OLIVIER M, HOLLSTEIN M, HAINAUT P. TP53 mutations in human cancers: origins, consequences, and clinical use. Cold Spring Harb Perspect Biol 2010; 2: a001008. http:// dx.doi.org/10.1101/cshperspect.a001008

[22] TORNESELLO ML, BUONAGURO L, BUONAGURO FM. Mutations of the TP53 gene in adenocarcinoma and squamous cell carcinoma of the cervix: a systematic review. Gynecol Oncol 2013; 128: 442-448. http://dx.doi.org/10.1016/j. ygyno.2012.11.017

[23] BUSBY-EARLE RM, STEEL CM, WILLIAMS AR, COHEN B, BIRD CC. p53 mutations in cervical carcinogenesis--low frequency and lack of correlation with human papillomavirus status. Br J Cancer 1994; 69: 732-737. http://dx.doi. org/10.1038/bjc. 1994.138

[24] SOONTHORNTHUM T, ARIAS-PULIDO H, JOSTE N, LOMO L, MULLER C et al. Epidermal growth factor receptor as a biomarker for cervical cancer. Ann Oncol 2011; 22: 2166-2178. http://dx.doi.org/10.1093/annonc/mdq723

[25] KUGLIK P, KASIKOVA K, SMETANA J, VALLOVA V, LASTUVKOVA A et al. Molecular cytogenetic analyses of hTERC (3q26) and MYC (8q24) genes amplifications in correlation with oncogenic human papillomavirus infection in Czech patients with cervical intraepithelial neoplasia and cervical carcinomas. Neoplasma 2015; 62: 130-139. http://dx.doi. org/10.4149/neo 2015017

[26] TACHEZY R, DAVIES P, ARBYN M et al. Consensus recommendations for cervical cancer prevention in the Czech Republic: a report of the International Conference on Human Papillomavirus in Human Pathology (Prague, 1-3 May 2008). J Med Screen 2008; 15: 207-210. http://dx.doi.org/10.1258/jms.2008.008057

[27] MA YY, WEI SJ, LIN YC, LUNG JC, CHANG TC et al. PIK3CA as an oncogene in cervical cancer. Oncogene 2000; 19: 2739-2744. http://dx.doi.org/10.1038/sj.onc.1203597
[28] KARAKAS B, BACHMAN KE, PARK BH. Mutation of the PIK3CA oncogene in human cancers. Br J Cancer 2006; 94: 455-459. http://dx.doi.org/10.1038/sj.bjc.6602970

[29] MURAYAMA-HOSOKAWA S, ODA K, NAKAGAWA S, ISHIKAWA S, YAMAMOTO $S$ et al. Genome-wide singlenucleotide polymorphism arrays in endometrial carcinomas associate extensive chromosomal instability with poor prognosis and unveil frequent chromosomal imbalances involved in the PI3-kinase pathway. Oncogene 2010; 29: 1897-1908. http://dx.doi.org/10.1038/onc.2009.474

[30] DAN S, OKAMURA M, SEKI M, YAMAZAKI K, SUGITA $\mathrm{H}$ et al. Correlating phosphatidylinositol 3-kinase inhibitor efficacy with signaling pathway status: in silico and biological evaluations. Cancer Res 2010; 70: 4982-4994. http://dx.doi. org/10.1158/0008-5472.CAN-09-4172

[31] CASTANEDA CA, LOPEZ-ILASACA M, PINTO JA, CHIRINOS-ARIAS M, DOIMI F et al. PIK3CA mutations in Peruvian patients with HER2-amplified and triple negative non-metastatic breast cancers. Hematol Oncol Stem Cell Ther 2014; 7: 142-148. http://dx.doi.org/10.1016/j. hemonc.2014.09.007

[32] WHYTE DB, HOLBECK SL. Correlation of PIK3Ca mutations with gene expression and drug sensitivity in NCI-60 cell lines. Biochem Biophys Res Commun 2006; 340: 469-475. http://dx.doi.org/10.1016/j.bbrc.2005.12.025

[33] ISAKOFF SJ, ENGELMANN JA, IRIE HY, LUO J, BRACHMANN SM et al. Breast cancer-associated PIK3CA mutations are oncogenic in mammary epithelial cells. Cancer Res 2005; 65: 10992-11000. http://dx.doi.org/10.1158/0008-5472.CAN$\underline{05-2612}$

[34] KANG S, BADER AG, VOGT PK. Phosphatidylinositol 3-kinase mutations identified in human cancer are oncogenic. Proc Natl Acad Sci U S A 2005; 102: 802-807. http://dx.doi. org/10.1073/pnas.0408864102

[34] MIYAKE T, YOSHINO K, ENOMOTO T, TAKATA T, UGAKI $\mathrm{H}$ et al. PIK3CA gene mutations and amplifications in uterine cancers, identified by methods that avoid confounding by PIK3CA pseudogene sequences. Cancer Lett 2008; 261: 120-126. http://dx.doi.org/10.1016/j. canlet.2007.11.004

[35] DERAKHSHANDEH-PEYKAR P, ALIVI J, HOSSEINNEZHAD A, RAUTENSTRAUSS B, VESAL RE et al. High frequency of mutations in the PIK3CA gene helical and kinase coding regions in a group of Iranian patients with high-grade glioblastomas: five novel mutations. J Neurogenet 2011; 25: 189-194. http://dx.doi.org/10.3109/01677063.2011.623202

[36] TOL J, DIJKSTRA JR, KLOMP M, TEERENSTRA S, DOMMERHOLT $M$ et al. Markers for EGFR pathway activation as predictor of outcome in metastatic colorectal cancer patients treated with or without cetuximab. Eur J Cancer 2010; 46: 1997-2009. http://dx.doi.org/10.1016/j.ejca.2010.03.036

[37] HOU MM, LIU X, WHELER J, NAING A, HONG D et al. Targeted PI3K/AKT/mTOR therapy for metastatic carcinomas of the cervix: A phase I clinical experience. Oncotarget 2014; 5: 11168-11179. http://dx.doi.org/10.18632/oncotarget.2584

[38] JANKU F, WHELER JJ, WESTIN SN, MOULDER SL, NAING A et al. PI3K/AKT/mTOR inhibitors in patients with breast 
and gynecologic malignancies harboring PIK3CA mutations. J Clin Oncol 2012; 30: 777-782. http://dx.doi.org/10.1200/ LCO.2011.36.1196

[39] WEGMAN P, AHLIN C, SORBE B. Genetic alterations in the $\mathrm{K}$-Ras gene influence the prognosis in patients with cervical cancer treated by radiotherapy. Int J Gynecol Cancer 2011; 21 : 86-91. http://dx.doi.org/10.1097/IGC.0b013e3182049924

[40] PAPPA KI, CHOLEZA M, MARKARI S, GIANNIKAKI E, KYROUDI A et al. Consistent absence of BRAF mutations in cervical and endometrial cancer despite KRAS mutation status. Gynecol Oncol 2006; 100: 596-600. http://dx.doi. org/10.1016/j.ygyno.2005.09.029

[41] BUYRU N, TEZOL A, DALAY N. Coexistence of K-ras mutations and HPV infection in colon cancer. BMC Cancer 2006; 6: 115. http://dx.doi.org/10.1186/1471-2407-6-115

[42] KERSEMAEKERS AM, FLEUREN GJ, KENTER GG, VAN DEN BROEK LJ, ULJEE SM et al. Oncogene alterations in carcinomas of the uterine cervix: overexpression of the epidermal growth factor receptor is associated with poor prognosis. Clin Cancer Res 1999; 5: 577-586.

[43] MARCHANT J, MANGE A, LARRIEUX M, COSTES V, SOLASSOL J. Comparative evaluation of the new FDA approved THxID-BRAF test with High Resolution Melting and Sanger sequencing. BMC Cancer 2014; 14: 519. http://dx.doi. org/10.1186/1471-2407-14-519

[44] BILBAO-SIEYRO C, SANTANA G, MORENO M, TORRES L, SANTANA-LOPEZ G ET AL. High resolution melting analysis: a rapid and accurate method to detect CALR mutations. PLoS One 2014; 9: e103511. http://dx.doi.org/10.1371/ journal.pone.0103511

[45] SHI YEEN TN, PATHMANATHAN R, SHIRAN MS, AHMAD ZAID FA, CHEAH YK. Detection of epidermal growth factor receptor mutations in formalin fixed paraffin embedded biopsies in Malaysian non-small cell lung cancer patients. J Biomed Sci 2013; 20: 22. http://dx.doi.org/10.1186/1423$\underline{0127-20-22}$ 


\begin{tabular}{|c|c|c|c|c|}
\hline Gene & Hotspot & & Sequence & Amplicon \\
\hline \multirow[t]{6}{*}{ PIK3CA } & codon 88 & forward & AAGTGTTACTCAAGAAGCAGAAAGG & \multirow{2}{*}{234 bp } \\
\hline & & reverse & ACGAAGGTATTGGTTTAGACAGAAA & \\
\hline & \multirow[t]{2}{*}{ codons $542-546$} & forward & AGCTAGAGACAATGAATTAAGGGAAA & \multirow{2}{*}{$133 \mathrm{bp}$} \\
\hline & & reverse & TCTCCATTTTAGCACTTACCTGTGAC & \\
\hline & \multirow[t]{2}{*}{ codons 1043-1047 } & forward & TCTTTTGATGACATTGCATACATTC & \multirow{2}{*}{$197 \mathrm{bp}$} \\
\hline & & reverse & CAGAGTGAGCTTTCATTTTCTCAGT & \\
\hline \multirow[t]{2}{*}{ KRAS } & codons 12,13 & forward & CTGAATATAAACTTGTGGTAGTTGGA & \multirow{2}{*}{166 bp } \\
\hline & & reverse & TTTATCTGTATCAAAGAATGGTCCTG & \\
\hline \multirow[t]{10}{*}{$E G F R$} & exon 18 & forward & TACATTTGTCCTTCCAAATGAGC & \multirow{2}{*}{298 bp } \\
\hline & & reverse & CCTGTGCCAGGGACCTTAC & \\
\hline & \multirow[t]{2}{*}{ exon 19} & forward & TTAACGTCTTCCTTCTCTCTCTGTC & \multirow{2}{*}{$250 \mathrm{bp}$} \\
\hline & & reverse & GAAAGTGAACATTTAGGATGTGGAG & \\
\hline & \multirow[t]{2}{*}{ exon $20\left(1^{\text {st }}\right.$ part $)$} & forward & GTATTTTGAAACTCAAGATCGCATT & \multirow{2}{*}{$250 \mathrm{bp}$} \\
\hline & & reverse & GTCTTTGTGTTCCCGGACATAGT & \\
\hline & \multirow[t]{2}{*}{ exon 20 (2 $2^{\text {nd }}$ part $)$} & forward & CACCGTGCAGCTCATCAC & \multirow{2}{*}{$140 \mathrm{bp}$} \\
\hline & & reverse & CGTATCTCCCTTCCCTGATTAC & \\
\hline & \multirow[t]{2}{*}{ exon 21} & forward & ATTCGGATGCAGAGCTTCTT & \multirow{2}{*}{$300 \mathrm{bp}$} \\
\hline & & reverse & TTAAACAATACAGCTAGTGGGAAGG & \\
\hline \multirow[t]{6}{*}{ TP53 } & codons $173-181$ & forward & ATCTACAAGCAGTCACAGCACAT & \multirow{2}{*}{157 bp } \\
\hline & & reverse & CTAAGAGCAATCAGTGAGGAATCAG & \\
\hline & codons 245-249 & forward & GTTATCTCCTAGGTTGGCTCTGACT & \multirow{2}{*}{119 bp } \\
\hline & & reverse & GAGTCTTCCAGTGTGATGATGGT & \\
\hline & codons 273-282 & forward & TAGTGGTAATCTACTGGGACGGAAC & \multirow{2}{*}{149 bp } \\
\hline & & reverse & CTTGCTTACCTCGCTTAGTGCT & \\
\hline
\end{tabular}

Supplementary Table 1.: Primer pairs for HRM analyses. 


\begin{tabular}{|c|c|c|c|c|}
\hline Gene & Hotspot & & Sequence & $\begin{array}{c}\text { Amplicon } \\
\text { length }\end{array}$ \\
\hline \multirow[t]{6}{*}{ PIK3CA } & codon 88 & forward & TTTGGGACAACCATACATCTAATTC & \multirow{2}{*}{514 bp } \\
\hline & & reverse & ACGAAGGTATTGGTTTAGACAGAAA & \\
\hline & codons 542-546 & forward & GAGGAAAAGTAAATTGTTCACTACCA & \multirow{2}{*}{468 bp } \\
\hline & & reverse & TCTCCATTTTAGCACTTACCTGTGAC & \\
\hline & codons 1043-1047 & forward & TAAAGGGAATCAAAAGATGTTGGTA & \multirow{2}{*}{$551 \mathrm{bp}$} \\
\hline & & reverse & AATTCTAATGCTGTTCATGGATTGT & \\
\hline \multirow[t]{2}{*}{ KRAS } & codons 12,13 & forward & TACAGTTCATTACGATACACGTCTG & \multirow{2}{*}{$560 \mathrm{bp}$} \\
\hline & & reverse & CTCTGAAATACACTTCCAATCAAAA & \\
\hline \multirow[t]{8}{*}{ EGFR } & exon 18 & forward & TTTCTACCAACTTCTGTCAAGCTCT & \multirow{2}{*}{$545 \mathrm{bp}$} \\
\hline & & reverse & ATAAAAATGCCTTTGGTCTGTGAAT & \\
\hline & exon 19 & forward & CAGCATCATTAAATTCTGGATGAA & \multirow{2}{*}{$561 \mathrm{bp}$} \\
\hline & & reverse & TGTCTCTAAGGGGAGGGAGTTATAC & \\
\hline & exon 20 & forward & GTATTTTGAAACTCAAGATCGCATT & \multirow{2}{*}{$554 \mathrm{bp}$} \\
\hline & & reverse & CACACTGAGCACTCAATAAAGAGAA & \\
\hline & exon 21 & forward & CTTTCCATTCTTTGGATCAGTAGTC & \multirow{2}{*}{$581 \mathrm{bp}$} \\
\hline & & reverse & GAGAGACTGAAACCTAACATTTGCT & \\
\hline \multirow[t]{6}{*}{ TP53 } & codons 173-181 & forward & AАCTCTGTCTCCTTCCTCTTCCTAC & \multirow{2}{*}{$550 \mathrm{bp}$} \\
\hline & & reverse & GTTAAACCCATTTACTTTGCACATC & \\
\hline & codons 245-249 & forward & CTGTGTTATCTCCTAGGTTGGCTCT & \multirow{2}{*}{$291 \mathrm{bp}$} \\
\hline & & reverse & AGAAAACTGAGTGGGAGCAGTAAG & \\
\hline & codons 273-282 & forward & TTCTTCCATACTACTACCCATCCAC & \multirow{2}{*}{$571 \mathrm{bp}$} \\
\hline & & reverse & AAGACTTAGTACCTGAAGGGTGAAA & \\
\hline
\end{tabular}

Supplementary Table 2. Primer pairs for standard PCR and Sanger sequencing. 